\title{
Orevisto
}

ISSN n² 2447-4266

Vol. 4, n. 1, Janeiro-Março. 2018

DOI: http://dx.doi.org/10.20873/uft.2447-4266.2018v4n1p89

\section{FISSURAR A \\ EDUCAÇÃO POR ENTRE \\ ESCRITA DERIVA...}

FISSURE EDUCATION THROUGH WRITE-DRIFT...

\author{
FISSURAR LA EDUCACIÓN POR \\ ENTRE ESCRITA DERIVA...
}

\section{Alda Regina Tognini Romaguera ${ }^{1}$ Maria dos Remédios de Brito ${ }^{2,3}$}

\section{RESUMO}

Uma escrita e uma educação que apresentem digressão e apostem na criação de palavras, de uma escrita singular; um entretecer e entremear e entrever planos gerados por encontros e forças que possam compor outros chãos para a educação por meio de uma escrita-deriva, como aquilo que resiste e inventa um povo por vir. Para isso é necessário gaguejar a linguagem, as palavras, a sintaxe e fazer linhas de fuga, percorrendo o meio, as margens, sem o horror das descertezas, das ausências, dos vazios, nos intervalos fazendo variar a educação

\footnotetext{
${ }^{1}$ Doutora em Educação pela Faculdade de Educação da Unicamp (2010), atua na área de: Educação, Conhecimento, Linguagem e Arte. É pesquisadora do Laboratório de Estudos Audiovisuais OLHO (FE - Unicamp) e do grupo CNPq "multiTÃO: prolifer-artes sub-vertendo ciências, educações e comunicações" (Labjor e F.E/Unicamp; DEDU/Uefs; Dpto de Filosofia/UFRN). Participa do projeto de pesquisa "In-ventos por entre Áfricas, literaturas e imagens" e coordena o Grupo de estudos RITMOS: Estética no Cotidiano Escolar. Participa do "Coletivo Fabulografias" como membro da equipe executora, na criação e montagem de exposições. Desenvolve projetos de pesquisa e é professora pesquisadora da Universidade de Sorocaba - UNISO. (alda.romaguera@prof.uniso.br)

${ }_{2}$ Possui graduação em Pedagogia e em Filosofia pela Universidade Federal do Pará (UFPA), Pósdoutora em Filosofia da Educação pela Universidade Estadual de Campinas (UNICAMP). Atualmente, é professora associada da Universidade Federal do Pará, no Instituto de Educação Matemática e Científica, atuando na graduação e pós-graduação do mesmo Instituto. (mrb@ufpa.br/mrdbrito@hotmail.com)

3 Endereço de contato das autoras (por correio): Universidade de Sorocaba, Programa de Mestrado e Doutorado em Educação. Rodovia Raposo Tavares km 92,5 Vila Artura, CEP: 18023000 - Sorocaba, SP - Brasil.
} 


\section{Observatónio}

ISSN n² 2447-4266

Vol. 4, n. 1, Janeiro-Março. 2018

DOI: http://dx.doi.org/10.20873/uft.2447-4266.2018v4n1p89

representacional. Com Deleuze, tomar da arte aquilo que resiste, e resistir educação por um estilo de escrita. Explorar na arte o conceito de resistência e fazer conexões com a escrita singular.

PALAVRAS-CHAVE: Educação; Linguagem; Escrita.

\section{ABSTRACT}

A writing and an education that presents digression and bet on the creation of words, of a singular writing; An interweaving and intermingling and glimpsing plans generated by encounters and forces that can compose other grounds for education through a writing-drift, as that which resists and invents a people to come. For this it is necessary to stutter language, words, syntax and make escape lines, traversing the middle, the margins, without the horror of the uncertainties, the absences, the voids, in the intervals making representational education vary. With Deleuze, take from art what resists, and resist education by a style of writing. Explore in art the concept of resistance and make connections with singular writing.

KEYWORDS: Education; Language; Writing.

\section{RESUMEN}

Escrita y una enseñanza, que han recorrido y el interés en la creación de palabras, una escritura singular; uno planes de tejido y entretejen y vislumbrar generados por las reuniones y las fuerzas que pueden componer otros motivos de la educación a través de una escritura derivan, como la que se resiste y se inventa un pueblo del futuro. Esto requiere el lenguaje tartamudeo, las palabras, la sintaxis y escapan líneas, cubriendo el medio ambiente, los bancos, sin el horror de descertezas, de ausencias, el vacío, los intervalos variables de educación representacional. Con Deleuze, llevar el arte que resistir, resistir y educación para un estilo de escritura. Explora la técnica, el concepto de resistencia y hacer conexiones con la escritura singular. 


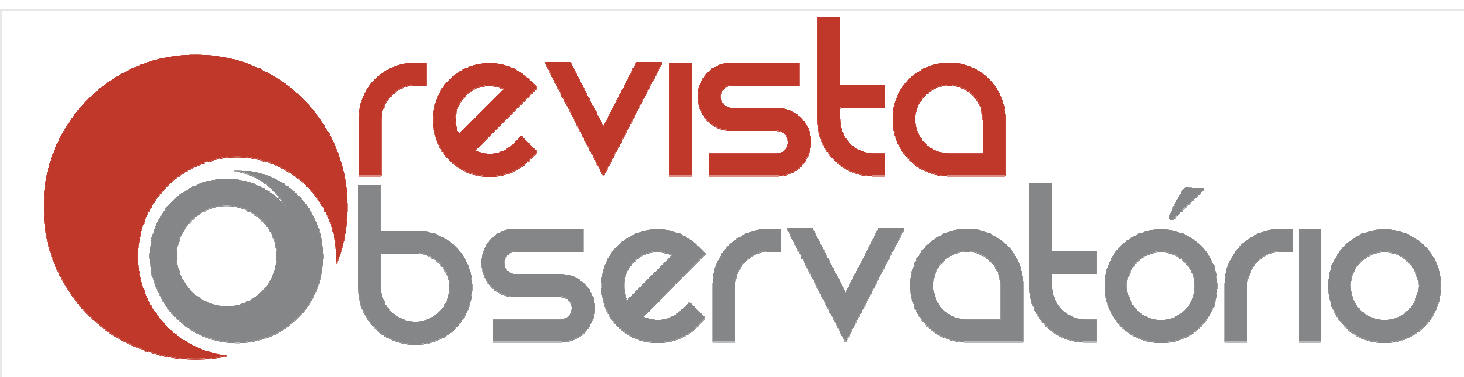

ISSN n² 2447-4266

Vol. 4, n. 1, Janeiro-Março. 2018

DOI: http://dx.doi.org/10.20873/uft.2447-4266.2018v4n1p89

PALABRAS CLAVE: Educación; Linguaje; Escritura.

Recebido em: 05.10.2017. Aceito em: 01.12.2017. Publicado em: 01.01.2018. 


\section{Observatónio}

ISSN n² 2447-4266

Vol. 4, n. 1, Janeiro-Março. 2018

DOI: http://dx.doi.org/10.20873/uft.2447-4266.2018v4n1p89

\section{Escriturar um bloco de entrada}

O que significa pensar a educação pela singularidade e na singularidade? Ou mesmo por devires? A singularidade em Rolnik e Guattari (2006) é um conceito existencial. Diz respeito a diferentes maneiras de existir e se contrapõe ao conceito de identidade como referenciação.

Não se fala de um "eu", de um sujeito portador do conhecimento, mas de multiplicidades. Também o conceito não remete a subjetividades fixas e nem a consciência. Há aqui o giro flutuante de um campo transcendental impessoal e pré-individual. Com isso, não se pode conceber um "eu" e nem uma individualidade.

Sendo assim, o que não é pessoal e nem individual são campos de singularidades sempre se fazendo por meio de uma superfície imanente. As singularidades são os acontecimentos e são atualizadas por meio de um jogo de forças, de encontros com signos disparando verdadeiros movimentos acontecimentais. Essas singularidades se fazem por heterogeneidades que não entram em campos estáveis, sempre são móveis, processuais, sem unificação, seu elemento é o paradoxal, não percorrem o fundo, lidam com a superfície e bordas diante das topologias dos contatos, dos encontros, dos afetos e dos sentidos. "O vivo vive no limite de si mesmo..." (Deleuze, 2007, p. 106)

Se ficarmos restritos a coordenadas representacionais e dogmáticas que (en)travam modos de existir, não nos aproximamos de possibilidades de singularização. Do mesmo modo que se pode entrar pelo meio. Sim, pois devir não é regredir e nem progredir, é simplesmente um intermezzo, um movimento nômade, variante, pondo em desconforto as certezas, as polaridades que contaminam a educação representacional. Não se muda por progressão, mas por criação, maquinações... 


\section{revisto}

ISSN n² 2447-4266

Vol. 4, n. 1, Janeiro-Março. 2018

DOI: http://dx.doi.org/10.20873/uft.2447-4266.2018v4n1p89

O presente texto pretende transpassar forças criativas, mas não se presta a traçar caminhos nem receitas; quer provocar porosidades e fissurar 0 monolítico bloco de ideias que transitam nos espaços da educação formal. Deseja inserir no campo da educação movimentos de pensamento que entrem em composições com imagens escritas, resistindo à forma-modelação. Quer cavar buracos no entre tempo da educação dogmática e da sua linguagem, por entre palavras-escritas des-re-criadoras do real na linguagem, pelo fora da linguagem, como que se fizesse resistência pelo pensamento.

A ideia que se defende entre essas escrituras é a de que pela criação na linguagem, se resiste a uma educação unificante e formadora que faz da palavra dogma, palavra ordem, comando. Pensando outras formas de expressão, a escrita pode gaguejar a linguagem, fissurar os estabelecimentos codificantes que passariam por blocos de singularizações.

\section{Topos escrita-devir}

Deleuze se interessava por uma escrita onda, escrita experimental e cristalina. Ele talvez pudesse dizer que Marguerite Duras faz tal escrita, de algum modo. Pois, como a autora diz: "A história da minha vida não existe. Ela não existe. Nunca há um centro. Nem caminho, nem linha" (DURAS, M. 2007, p. 12). O escritor para Deleuze é esse que deseja a dissolução de si mesmo, sendo assim, nas palavras de Duras...

[...] a escrita não é uma maneira de conseguir viver, é simplesmente uma maneira de viver. Nem todos podem escrever ou fazer literatura, essa vida não é para todo mundo. Alguns morrem por ela. Mais do que uma maneira de viver, a literatura é uma maneira de morrer, de morrer para si mesmo. (DURAS, 2007, p. 90). 


\section{Observatónio}

ISSN n² 2447-4266

Vol. 4, n. 1, Janeiro-Março. 2018

DOI: http://dx.doi.org/10.20873/uft.2447-4266.2018v4n1p89

Deleuze talvez assinasse esse pensamento sem inclinações ou receios. A escrita, para este autor, é um modo de estar na vida, uma vida que se desenha no horizonte daquele que a experimenta entre traçados, entre gestos e encontros. Ela opera por uma força, por uma potência, por uma zona de experimentação que passa efetivamente pelo corpo do escritor, que o faz produzir um devir escrita, desmobilizando os sentidos, fissurando o papel em branco.

Não há como capturar tudo aquilo que se escreve ou se pensa quando se narra, pois a palavra é sempre inapropriada, tal como o pensamento, que, como um córrego, torna-se uma espécie de zona indomável. A escrita não permite limite e forma para a linguagem, pois a palavra escrita ou narrada não completa o signo. O que se narra é um fluxo, o que se escreve é uma intensidade, não há como oferecer uma forma pura para o que é vida. Por isso, o escritor é aquele que desenha a sua vida por um modo esgarçado, percorre linhas sem saber a sua continuidade, nas quais $\mathrm{o}$ ato de escrever torna-se um movimento selvagem e a palavra se faz e desfaz-se, a linguagem gesta-se e se experimenta.

Escrever é sempre uma relação com a "ordem" do movimento, do inacabamento, do agenciamento, na qual o corpo da escrita vai se desmontando, montando-se, num efeito de territorializar e de desterritorializarse. Por isso, o ato da escrita não se refere a significar, mas, efetivamente, a agrimensar, a cartografar, mesmo que sejam regiões ainda por vir, como alerta Deleuze (2007). A vida passa pela escrita quando vai operando uma máquina de produção das intensidades que percorrem o entre, o devir, o meio. Sobre tal conceito dizem Deleuze e Guattari (1997 p. 18-19): "Um devir não é uma correspondência de relações. Mas tampouco é ele uma semelhança, uma imitação e, em última instância, uma identificação [...]". 


\section{Observatório}

ISSN n² 2447-4266

Vol. 4, n. 1, Janeiro-Março. 2018

DOI: http://dx.doi.org/10.20873/uft.2447-4266.2018v4n1p89

Pelo que Deleuze diz:

A escrita é inseparável do devir: ao escrever, estamos num devirmulher, num devir-animal ou vegetal, num devir-molécula, até num devir-imperceptível. Esses devires encadeiam-se uns aos outros segundo uma linhagem particular [...]. O Devir não vai no sentido inverso, e não entramos num devir-Homem, uma vez que o homem se apresenta como uma forma de expressão dominante que pretende impor-se a matéria, ao passo que mulher, animal ou molécula têm sempre um componente de fuga que se furta a sua própria formalização [...] Devir não é atingir uma forma (identificação, imitação, Mimese), mas encontrar a zona de vizinhança, de indiscernibilidade ou de indiferenciação [...] O devir está sempre "entre" ou "no meio"(DELEUZE, 2007, p. 11).

A escrita, assim, torna-se um atletismo, que se exerce na fuga, no desaparecimento, compondo uma relação entre morte e vida, perfazendo um movimento por entre lugares e formas; que vai arrastando as palavras, a linguagem, para um mundo desconhecido e inacabado. Há uma luta corporal junto à palavra. Nesse ínterim, pode-se dizer que escrever é sempre uma relação dessa ordem. Contudo, a escrita, a vida e o corpo não têm ligações com um sujeito, uma vez que ela vai desfazendo os órgãos, vai cortando membros e decepando cabeças. Como diz Deleuze ao se referir ao caso exemplar de Thomas Hardy na construção de seus personagens que não são sujeitos e nem pessoas,

As personagens nele não são pessoas ou sujeitos, são coleções de sensações intensivas, cada uma é uma coleção dessas, um pacote, um bloco de sensações variáveis. Há um curioso respeito pelo indivíduo, um respeito extraordinário: não porque ele se apreenda a si mesmo como uma pessoa, e seja reconhecido como uma pessoa [...], pelo contrário, porque ele se vive e porque vive os outros como outras tantas "possibilidades únicas" - a possibilidade única que tal ou tal combinação tenha sido produzida. Individuação sem sujeito. E estes pacotes de sensações vivas, estas coleções ou combinações, fogem por linhas de acaso ou de azar, aí onde se fazem os seus encontros, se necessário os seus maus encontros, que vão até à morte, até ao homicídio [...] (DELEUZE, 2004, p. 55). 


\section{revisto}

ISSN n² 2447-4266

Vol. 4, n. 1, Janeiro-Março. 2018

DOI: http://dx.doi.org/10.20873/uft.2447-4266.2018v4n1p89

$O$ ato de escrever percorre zonas. Textos-imagens se desfazem e resistem aos nomes, às formas, às normas e às leis. Cada escritor fabrica sua própria experiência com a escrita, com a imagem-texto, ao mesmo tempo em que fabrica seu desmoronamento. O corpo passa por uma força, uma potência percorrida pela imanência fugidia do devir. Escreve-se para alcançar uma espécie de zona de vizinhança, de indiscernibilidade.

[...] uma escrita-corpo, um corpo que dança, um corpo textual impenetrável. Impenetrabilidade que faz, porém, com que o leitor se deixe atravessar não pela reprodução deformada dos pensamentos, mas pelo ressentir, mediante o qual ele se abre à contaminação, recusando assim a compreensão de um pensamento violentado pela escrita (LINS, 2002, p. 26).

Com isso, a linguagem vai operando com sua incompletude e desenhando um corpo liso, experiências, movimentos, entre passagens, textos e personagens. A linguagem vai desmontando rastros e constrói um bilinguismo e arrasta a gagueira por entre perigos, que aproximam movimentos de resistências, de intervalos, promovendo um tempo menor, uma escrita menor ${ }^{4}$, o que demarca a efetiva seleção de Deleuze por determinados autores, que para ele são criadores de outra língua na sua própria língua e faz para si uma estilística escritural.

Tudo vai passando por uma espécie de arrombamento, encontros, acasos, voltas, ideias, violência, nos quais o escritor foge de qualquer possibilidade natural de pensamento e, por isso, ele está sempre no entre, entre devires, pois "não pensamos sem nos tornarmos outra coisa, outra coisa qualquer que não pensa, um animal, um vegetal, uma molécula, uma partícula,

\footnotetext{
${ }^{4}$ Sobre essa questão ver: DELEUZE, G.; GUATTAERI, F. In: Kafka: por uma literatura menor.
} 


\section{Observatónio}

ISSN n² 2447-4266

Vol. 4, n. 1, Janeiro-Março. 2018

DOI: http://dx.doi.org/10.20873/uft.2447-4266.2018v4n1p89

que regressem ao pensamento e o voltam a lançar" (DELEUZE, 1992, p. 42). O escritor sente todo o potencial das palavras que vai esburacando seu corpo "habitado por um medo desmesurado, ele espera o instante que o leve a abandonar os órgãos e enveredar pela inocência do devir, para um corpo não mais sufocado pelo organismo" (LINS, 2012, p. 109), pois, para Deleuze, todos os escritores que formam uma língua menor querem promover fluxos no interior do sistema linguístico fechado e estruturado.

Se não há uma naturalização na escrita, mas trabalho, maquinações, como pensar uma educação em deriva, que encontre na escrita uma linha nômade, linha fluxo? A educação dogmática perpassa por um código linguístico fechado, não se comunica na educação, quando o professor fala é para dar ordem, fazer representar, prescrever... Sair desse campo minado da lei e da moralidade não é fácil, mas entendemos a fundamental importância de por a educação em deriva, criar outros modos de lidar com a gramática, com a escrita de modo que nesse conjunto seja importante inventar componentes de expressão que não estejam ligados somente à feitura universalizante.

Uma educação pela singularidade a partir do componente escrita é essa que se esvai, mostra que a gramática é imperceptível, que nela não se toca na sua efetividade. A linguagem e a escrita estão sempre mortas. Ora, qual seria o motivo da escola desprezar as linguagens que não estão no adequado, na representação? Qual seria o terror que a educação tem de uma escrita não objetivada? Qual seria o horror de ler um texto, pensar uma escrita sem unidade? Sem objeto, sem identidade? Seria o receio de não mais outorgar seus poderes? Tudo que se tem são grafias do vivo. A escrita, a linguagem têm história e cultura, tem jogo e forma de poder que abrem uma impossibilidade... Pensar a logografia na educação! 


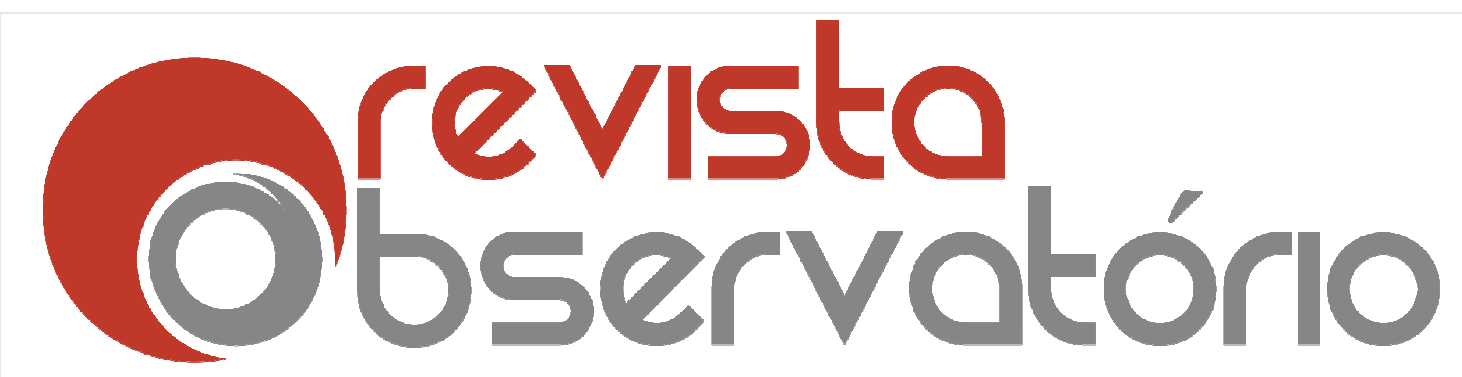

ISSN n² 2447-4266

Vol. 4, n. 1, Janeiro-Março. 2018

DOI: http://dx.doi.org/10.20873/uft.2447-4266.2018v4n1p89

\section{Educação e $(m)$ devires}

É possível ensaiar uma educação com/por uma escrita que devém? Deleuze (2008, p.11), responde em $A$ literatura e a vida: "A escrita é inseparável do devir: ao escrever, estamos num outro". Assim, estilo e $(m)$ resistência entram em composição para criar outros povos por vir. Criação de uma escrita

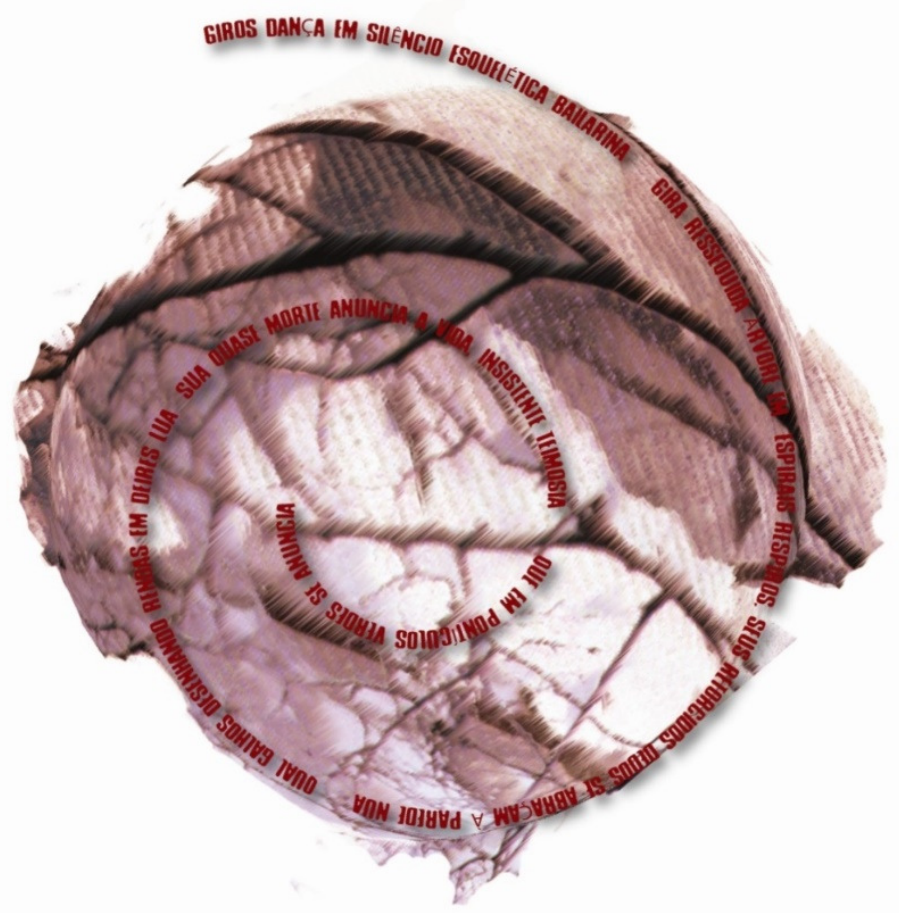
intensiva, que se faz "dança das palavras, viagem da língua na língua" (LINS, 2012, s/n), por palavras-gesto, prenhes de cores e sons. Giros. Dança.

A gramática entra em piruetas, a linguagem entra em um campo selvagem, ela deriva..., pois que decência entra na escrita?

Dança em silêncio esquelética bailarina

Gira ressequida árvore em espirais respiros Seus retorcidos dedos se abraçam à parede nua Qual galhos desenhando rendas em devires lua Sua quase morte anuncia a vida, insistente teimosia Que em pontículos verdes se anuncia

\footnotetext{
${ }^{5}$ Optou-se por grafar em itálico os poemas produzidos pela autora que aparecem ao longo do texto.
} 


\section{Observatónio}

ISSN n² 2447-4266

Vol. 4, n. 1, Janeiro-Março. 2018

DOI: http://dx.doi.org/10.20873/uft.2447-4266.2018v4n1p89

\section{Giro. Rodopio. Vertigem.}

Deleuze problematiza um pensamento que resiste na/pela criação. A capacidade criativa manifesta-se em ação política quando nos convida a pensála enquanto força de um corpo que resiste à submissão, contra todas as forças que, ao nos atravessarem, nos querem fracos, tristes, servos e tolos. Resistência que se faz na/pela força de criar, que se instala nas singularidades do acontecimento.

Ensaiar passos para uma dança com KaLahARi ${ }^{6}$, bebendo desejos de/por/com um(a) leitor(a) dançarino(a), ávido(a), de latejantes OLHOS a escutar: silêncios rumores; OUVIDOS de ver: radares sensores; BOCAS de cheirar: ventosas humores; NARIZES de comer: paladares vorazes. Ou seriam as palavras fluxos caleidoscópicos, matizes amalgamados de cosmos a criar sonoridades poéticas? Ou seriam bailarinos fluxos "cujos saltos ampliam a superfície do mundo e dos vocábulos" (LINS, 2007, p.104), a vegetAR, animalizAR, (trans)estelAR, vidAR sensações corpóreas em constelações rochosas, metálicas, aquosas, filosóficas, mitológicas, musicais? Nervuras dançantes a apostar na poética rítmica métrica de um povo porvir. VIDA a produzir e $(\mathrm{x})$ garçamentos rasgos ranhuras $\mathrm{e}(\mathrm{x})$ forços lamentos bordados texturas (se)mentes (si)lentes entranhas rasuras trans-par(en)tes vidas a e(x)pector(ar) vaz(AR). LOBA-mulher a m(olhar) escorrer suavidades em azul melancolia. LOBA-mulher dos suores azuis nas fronteiras dançantes de fluidos contornos em gotas deslizantes. LOBA-mulher: composição espelho azul ton sur ton. LOBA-mulher a m(olhar)-se em rios (a)fluir-se.

$\operatorname{voz}(e)$ rio

\footnotetext{
${ }^{6}$ Obra poética de Luis Serguilha, publicada em 2013 pela Editora Ofício das palavras.
} 


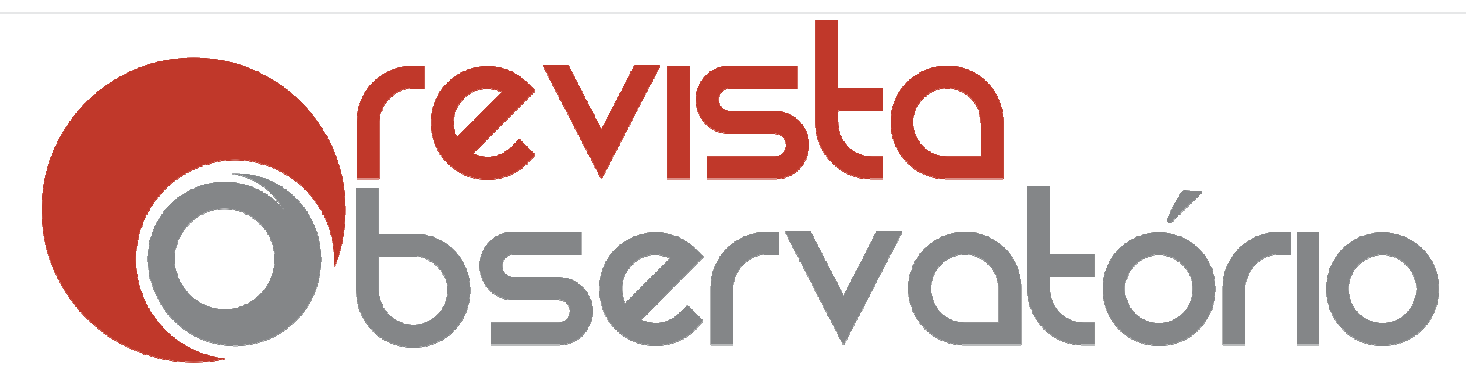

ISSN n² 2447-4266

Vol. 4, n. 1, Janeiro-Março. 2018

DOI: http://dx.doi.org/10.20873/uft.2447-4266.2018v4n1p89

emsimesm(ancor)ado

vozágua (des)anda

(des)água

en-sanguentado

sem voz nem nascente

água letra lítera

irmã da palavra

Palavra-dança, PALAVRÁGUAS com LISPECTOR. E a LOBA transmuta-se em águasvivas, moles, líquidas, fluidas a dançar anemonamente.

molejam entranhadas palavráguas no sem som de escuridão marinha gotas azuis águas quase vivas moles, líquidas, fluidas trans-luz-(em)-se pur'água brotando d'água entranhadamente misturam-se viajantes vidas navegantes por marinhas superficies palavráguas peles vazias, corpos contorno e fios lambem-se lambuzam-se de fogo molhado, mole, fluido vida palavra ardente água corrente palavraguadamente.

Dor surda cheirando a mangue, contornos plúmbeos e hálito pútrido; dor em silêncio viscoso entranhado e escuro encasulando a alma em mantos pétreos; cega, muda, em desamor, segue sem rumo carregando a imensidão do VAZIO e a frieza desértica dos abandonos. 


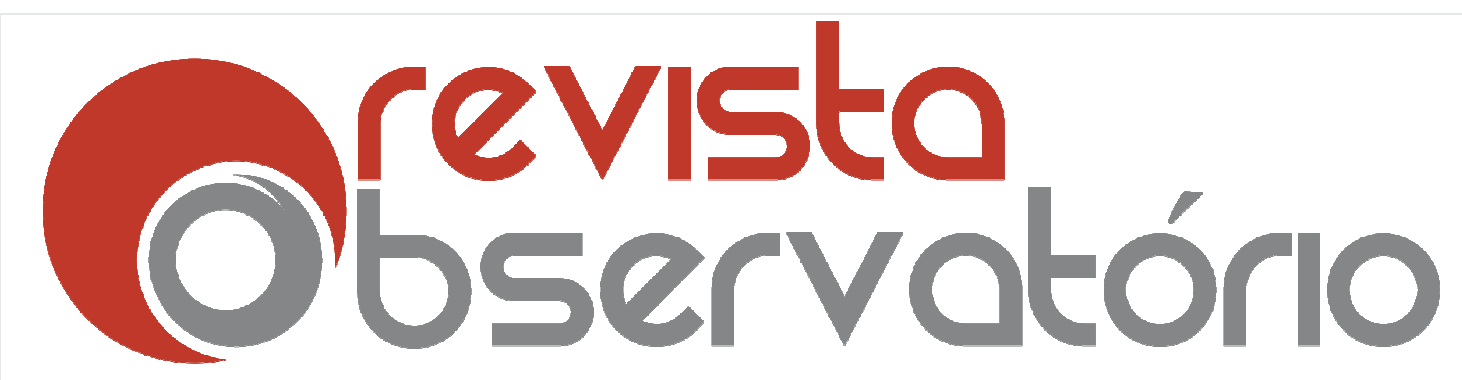

DOI: http://dx.doi.org/10.20873/uft.2447-4266.2018v4n1p89

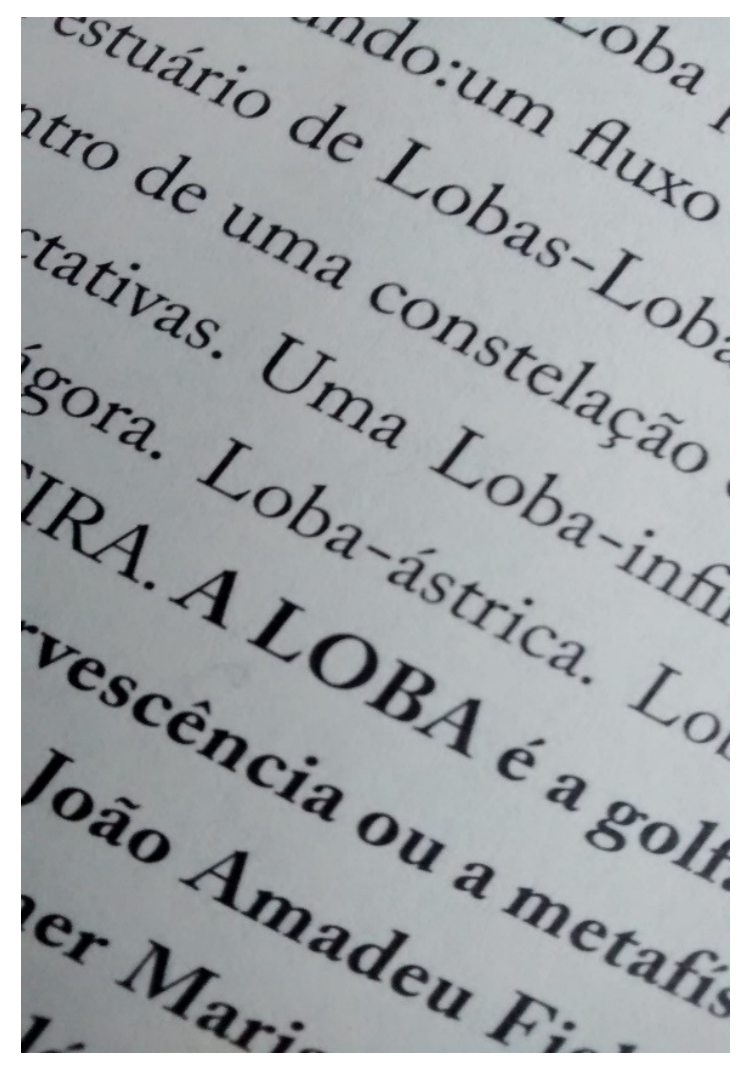

pupa lerda
Palavra-LOBA-em-gozo: uivos cores formas de ARP__ ruídos prenhes de líquens tribais nomadizando desérticas falas-fálicas. Glandes sêmens sê-mentes entranhas estrambólicas empapuçando verves primordiais. Interestelar canoa. turbilhonamento alucinante agramaticando a VIDA ÁVIDA vadia. Cosmo-agonia da língua. Palavra-larva lavra brota buraco esburaca fere en-ferruja rija PALARVA úmida musguenta carcomida es-permeada palarva pedra Larval instante oco luz rompendo densidão de nuvens cratera de raios clareira metálicos grunhidos cintilantes onomatopeicos prenhes empapuçados escaldantes

Penetração feérica ritual perfurante

Palavra-onda indo e vindo espocando espumas resmungando grãos

roncos surdos uivos turvos compassos respiração cósmica 


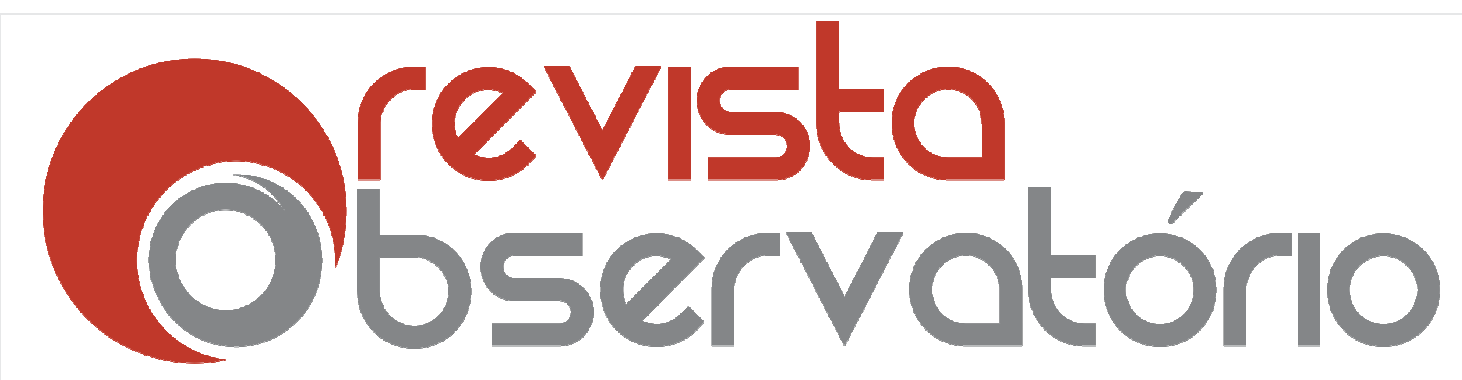

ISSN n² 2447-4266

Vol. 4, n. 1, Janeiro-Março. 2018

DOI: http://dx.doi.org/10.20873/uft.2447-4266.2018v4n1p89

infinitamente

mente fita desérticos pés

passos pass-passeiam invisiveis dunas

montículos negativos de ondas

esperma espinha espumas

desenham pegadas de encantados seres

presa nem e não estalagmítica caverna

gretas

gritam egos e ossos

\section{PALAVRONDA}

festa a en-frestar despenhadeiro milenar

amalgama silencia ecos

primitivos estrambólicos sons

Travessia cosmogonia

Palavra-vara tesa lisa intumescida lavra noturnos urros empapuça gordas veias salteia jorros

espumas

PALÁVARA espirra-pulsa brumas es-pumas brancas dançantes lias

leites gozos invaginando luas

\section{FULGURAÇÃo}

fogoar

pele poros página

amarelos laranjas lambendo nuvens

luzes de algodão vapores calores gotículas

palavrasnuvens cho

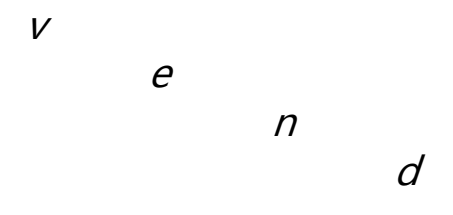

o 


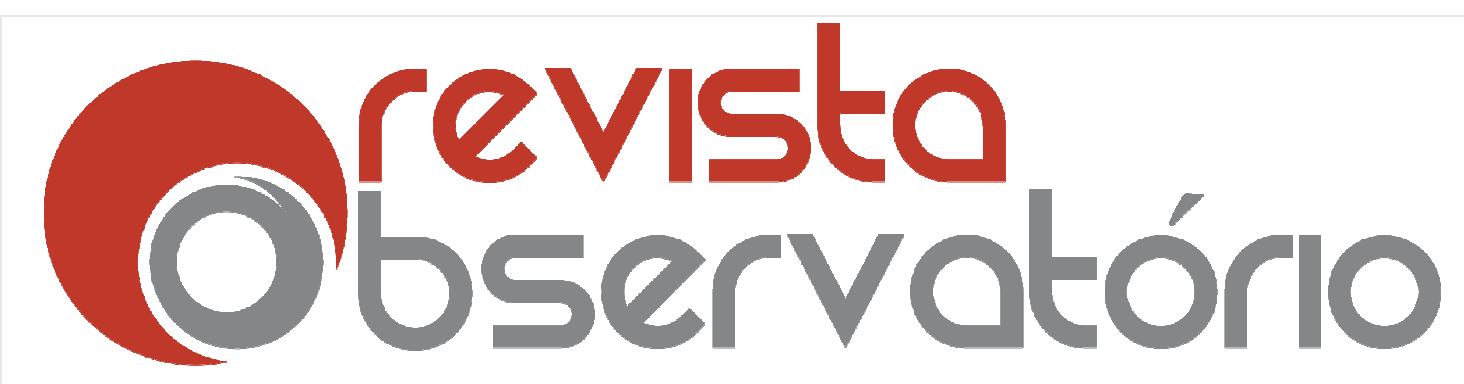

ISSN n² 2447-4266

Vol. 4, n. 1, Janeiro-Março. 2018

DOI: http://dx.doi.org/10.20873/uft.2447-4266.2018v4n1p89

Ondulando-se aos nossos pés, nuvens irradiam mares ondas crespas fofas fluidas fugazes. Abóbadas azuis iluminadas atravessadas em amarelos sóis esvoaçam pensamentos pássaros velozes...

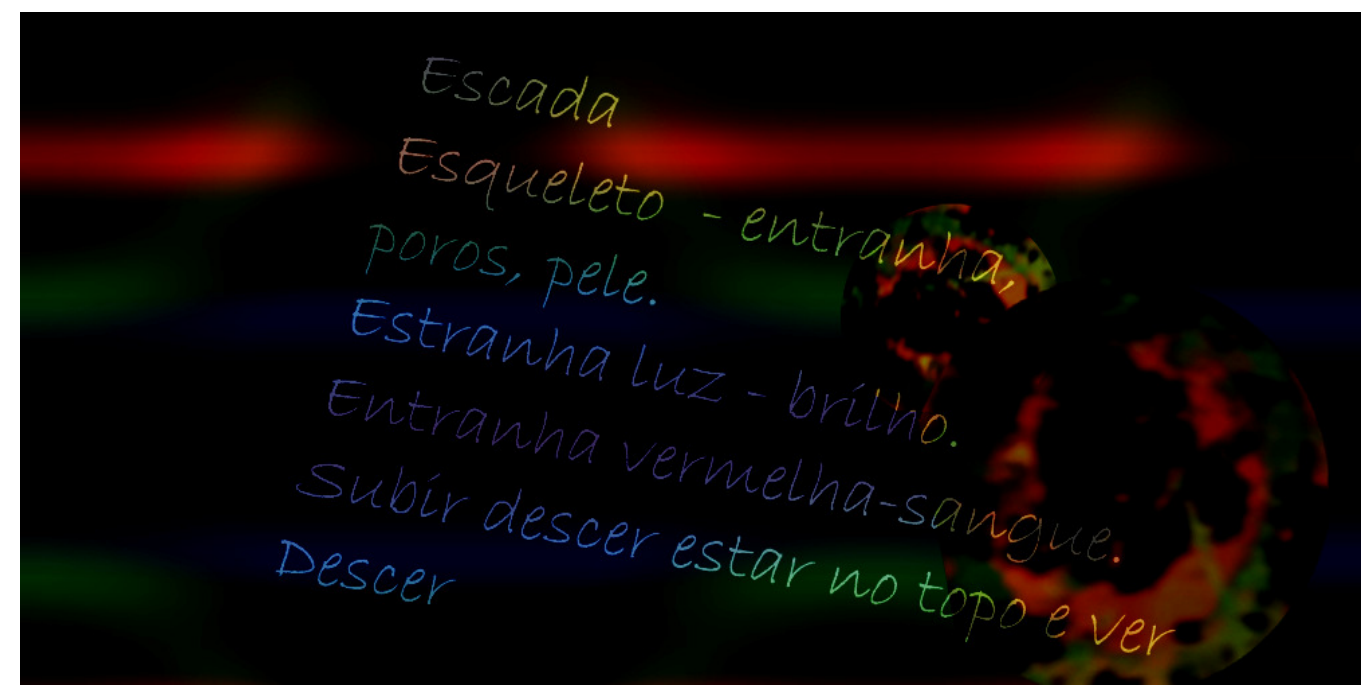

A escrita perde visibilidade... perde significações formais objetivas. A língua fica a nadar.

TRANSitar: (es)tar em trânsito e des-en-CON-trar, CON-versar

TRANSversar kafka, kafkar deleuze e EX-cre-VER, LER VER lamber ER, cheirar tocar AR, ouvir sentir IR EX-ist-IR no que se lê, LER através, atravess-AR, VERsar o avesso TRANS-VERter vozes, sub-VER-ter vocábulos LER... li-ter-AR TRANS-valor-AR 


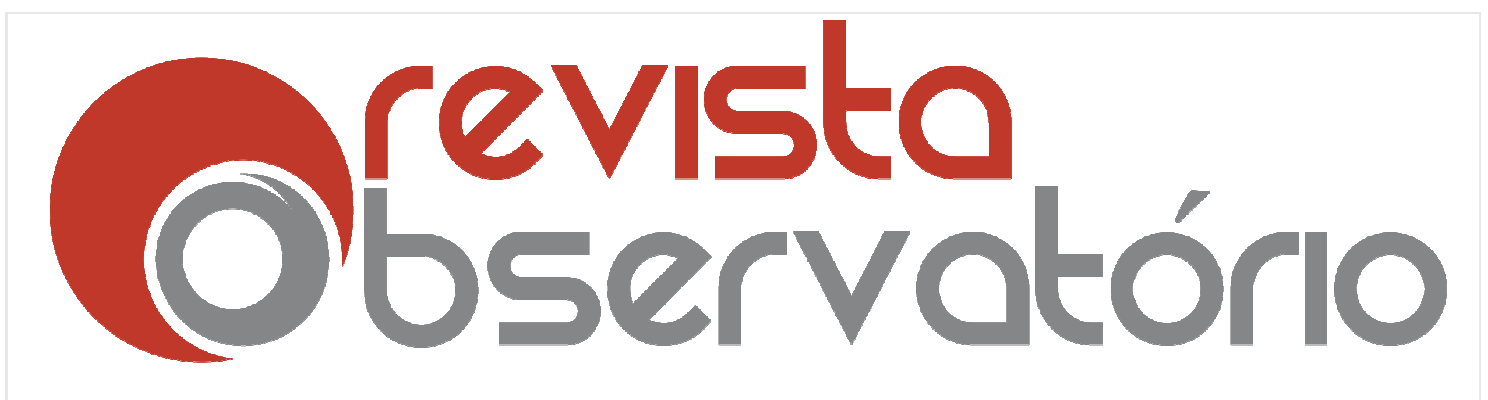

ISSN n² 2447-4266

Vol. 4, n. 1, Janeiro-Março. 2018

DOI: http://dx.doi.org/10.20873/uft.2447-4266.2018v4n1p89

VER-sar, ga-gue-jAR linguagens, Are-jAR minorAR educ-ações... RE- ações... $R E-E X$-ist-IR, resistindo minoridades $R E$-EX-ist-IR, existindo minoridades

Educação, Pedagogia, Cultura, Memória, Escola... Na busca pelo esvaziamento destes vocábulos, a tentativa de abrir espaços outros, de pensar sem representar.

Olhos de escutar: silêncios: rumores

Ouvidos de ver: radares: sensores Bocas pra cheirar: ventosas: humores Narizes de comer: paladares: vorazes

Palavras tecidas rasgadas em tiras, farrapos.

Palavras-resto esfarrapadas, farfalhando por superfícies manchadas, territórios molhados,espaços tingidos:varal de palavras borradas por jorros de tinta...

Farrapos piscantes, restos inconstantes, metamorfoseados: papa do de-trans-formar.

Deixar-se capturar pelos intervalos, permitir-se mergulhos de Alice nos passeios por si, ou no completamente fora de si; percorrer-se sem medo de abrir portas, de beber elixires ou de enfrentar jaguadartes, como se Lewis Carroll em Jabberwocky...

No esvaziamento da palavra educação, o corpo lexical faz passagens para a morte: 


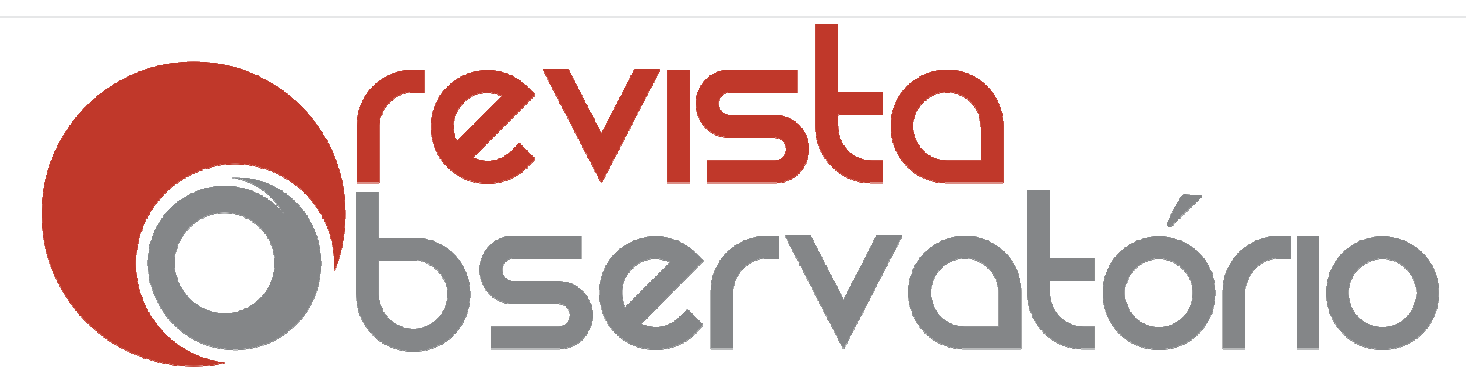

ISSN n² 2447-4266

Vol. 4, n. 1, Janeiro-Março. 2018

DOI: http://dx.doi.org/10.20873/uft.2447-4266.2018v4n1p89

Matéria: papéis, leis, material e trabalhos escolares;

Significados: discursos, conteúdos, explicações, currículo;

Sujeitos: identidades, igualdades, generalidades;

Tempos: da história, do cotidiano;

Espaços: escolas, instituições, políticas "como" coletividade do geral, generalizante...

Da palavra-valise forma derivam movimentos, ondulações semânticas prefixais que a negam ou a atravessam, sem, no entanto ultrapassá-la, perfurála, roubando-lhe o sentido. Aproximando este substantivo feminino - forma do outro - educação - foi possível ensaiar passos para uma dança vocabular.

Amorfar a forma, morfa. Se palavras nomeiam coisas e procedimentos, com Deleuze e sua proposta do pensamento por experimentação é possível pensar outras abordagens para as palavras, fora do campo da representação, tornando-as múltiplas. Operar na vivência, na duração intensa e intensiva de um tempo aiônico, do infinitivo do verbo. Com este procedimento, transformá-las em palavras pulsantes. Em seus pulsares, perceber matizes e nuances de cores, sons, formas, que abrem possibilidades para propor movimentos, danças vocabulares.

Enveredando "como um cavalo louco para uma escrita cujo devir é o devir-pensamento-musical da própria escrita" (LINS, 2012, s/n). Escrita rizomática $\mathrm{e}(\mathrm{m})$ educação que faz a língua tremer e o ruído entra entre as pernas, entre os braços, entre as cabeças, entre os seios da educação. $A$ educação vira corpo, vira tragédia, vira vida... Rosto desfeito! A palavra do educador, a escrita do diretor, a gramática do estudante viram escrituras, pois não podem comportar o ser, embora o desejem loucamente. 


\section{Observatónio}

ISSN n² 2447-4266

Vol. 4, n. 1, Janeiro-Março. 2018

DOI: http://dx.doi.org/10.20873/uft.2447-4266.2018v4n1p89

Não se escreve, todavia, com as lembranças; sequer com as lembranças de um povo por vir, salvo quando nossas recordações são aquelas de um povo rizomático, múltiplo, composto por imigrantes de todos os países, e não por um povo convocado para dominar o mundo. Trata-se de um povo menor, eternamente menor, tomado em um devir-revolucionário (LINS, 2012, s/n).

A escrita não permite limite e forma para a linguagem, pois a palavra escrita ou narrada não completa o signo. O que se narra é um fluxo, o que se escreve é uma intensidade, não há como oferecer uma forma pura para o que é vida. Por isso, o escritor é aquele que desenha a sua vida por um modo esgarçado, percorre linhas sem saber a sua continuidade, nas quais o ato de escrever torna-se um movimento selvagem e a palavra vai sendo desfeita, a linguagem vai sendo gestada e experimentada. A educação pode suportar essa via de escrita? Sempre cabe indagar: que logos habita o ventre da educação? Que fábula a atravessa?

\section{Desafio}

Des(a)fiar, não fiando mais no cotidiano concreto dos corredores, das palavras que des(con)fiam. Sem lembranças. De um lugar aleatório, pensar a experimentação como linha de fuga. Ins(pirando) com Hélio Oiticica: "minha posição foi sempre de que só o experimental é o que interessa, a mim não interessa nada que já tenha sido feito, a meu ver tudo isso é prelúdio para o que eu quero fazer, um novo tipo de coisa que não tenha nada a ver com os modelos..." (SALOMÃO, 2003, s/p).

Pensar educação acontecimental, "encontrar a zona de vizinhança, de indiscernibilidade..." tal que já não seja possível distinguir-se" (DELEUZE, 2008, p.11), fazendo "o múltiplo: simultaneamente conexões, heterogeneidades, 


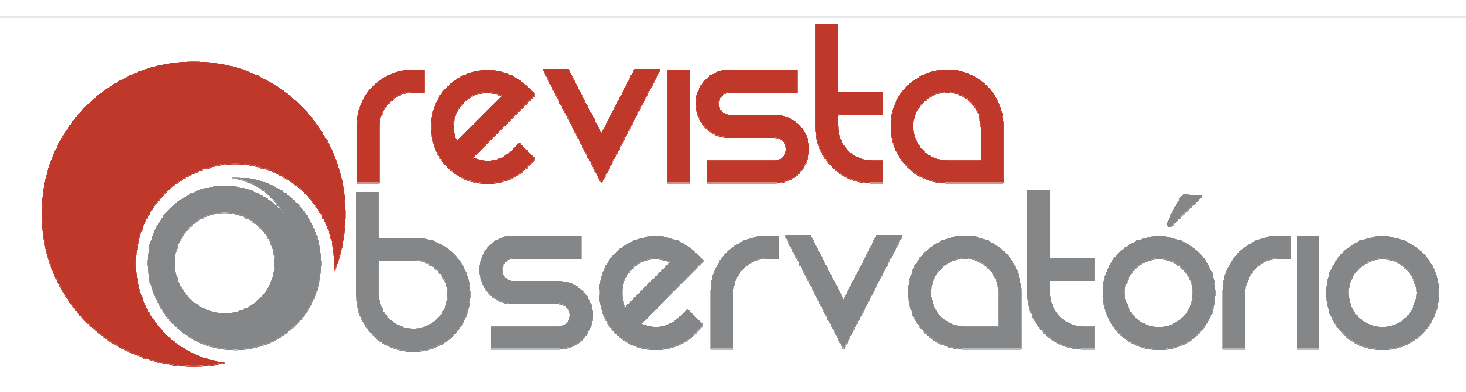

ISSN n² 2447-4266

Vol. 4, n. 1, Janeiro-Março. 2018

DOI: http://dx.doi.org/10.20873/uft.2447-4266.2018v4n1p89

multiplicidades e assignificâncias" (LINS, 2012, s/n). Ensaiar o pensamento entre outras linhas de escritas.

Movimentar uma vontade de resistir ao aprisionamento de ideias, ao modo como os discursos e as práticas instituídas nos capturam e nos paralisam, diminuindo possibilidades de inventar. Lançar-se ao desafio de romper com a reprodução, na tentativa de pensar com/por outros movimentos, que se fazem na/pela repetição que difere, como que em Heráclito devir, abrindo possibilidades de produzir pensamentos na educação.

Pensamentos que se propõem a dançar: conceitos em composições com criações de poemas resistem à forma-modelação, vida não orgânica que pode se manifestar nas linguagens, que escapa, aproximando termos desacostumados e contraditórios, paradoxais, que no plano educacional se estranham e criam des-certezas. Escapa ao abrir espaços de intervalo, nas fendas das práticas pedagógicas. Antes a-significar; hiatar, abrir brechas e criar cisões na e com a palavra.

Hiatar: Esvaziar e deixar vazio... Abrir brechas para o exercício de girar a linguagem, E escrever uma escrita outra. Escrever menormente: No menos, somente Em perigo, totalmente: Redemoinhando e dançando no meio da rua:

Gente

Gente Gente.

\section{Giros}

Considerando com Rancière que "O estado estético é pura suspensão, momento em que a forma é experimentada por si mesma. O momento de 


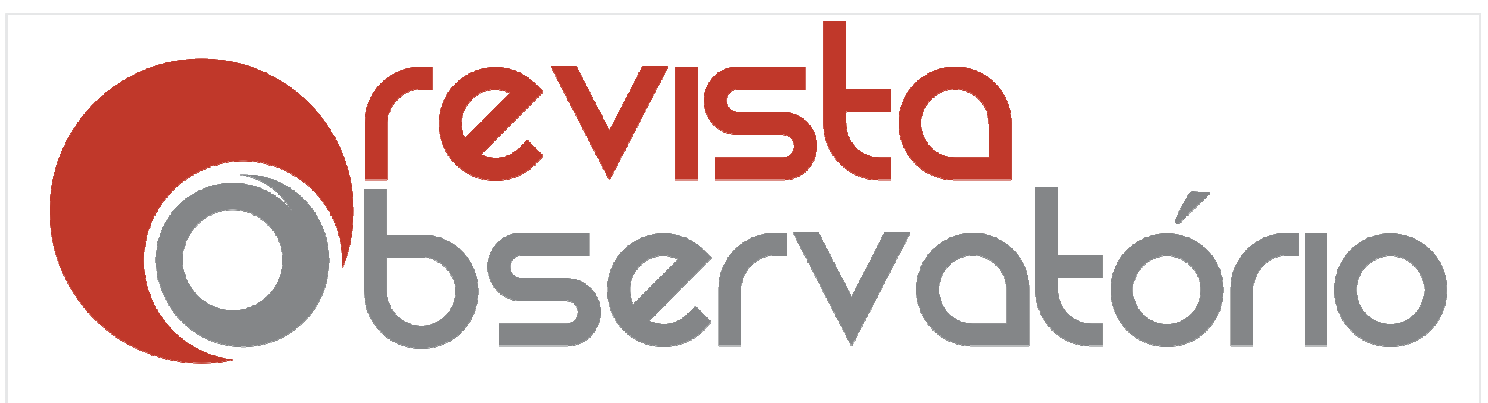

formação de uma humanidade específica" (2012, p. 34), gritar imagenspalavras-pensamentos e problematizar a força do Fora no $e$, por palavras e $(\mathrm{m})$ imagens a compor sensações cor, luz, giros e sons: e pela criação se resiste educação.

Da perambulação nômade por uma prosa poética, vulcânica e desértica, inventam-se pensamentos-jorros transpassados por intensidades. Ao ensaiar passos para uma dança com a Loba K'an de Serguilha, proliferam palavras de sentidos outros que se movimentam em criações vocabulares, como que bailarinas em êxtase, a rodopiar e saltar...

\section{Vazio}

O esvaziamento acontece por composições de escrita- silêncios. Desenformar a escrita - do lugar/prisão/território: Delírio verbal, que pega a palavra pela unha e a rasga, em gesto de cólera. No meio da rua habitada, enlouquecido furacão. Jorro, ventania que quer arruinar a verdade do dito e escrito. O logos dúvida! 


\section{revisto \\ Observatório}

DOI: http://dx.doi.org/10.20873/uft.2447-4266.2018v4n1p89

Boca

Abismal C

Ova

Es Vaz ia

Ed ucA cão

\section{Intervalos}

Agamben alimenta a ideia de um ser linguístico, ser-dito que é um conjunto e, ao mesmo tempo, uma singularidade, um hiato que só o artigo pode preencher, definido/indefinindo... "num espaço vazio em que sua vida é inqualificável e inesquecível. Esta vida é a vida puramente linguística. Só a vida na palavra é inqualificável e inesquecível. O ser exemplar é o ser puramente linguístico" (AGAMBEN, 1993, p.16). Com Deleuze: "Essa vida indefinida não tem ela própria, momentos, por mais próximos que estejam uns dos outros, mas apenas entre-tempos, entre momentos" (DELEUZE, 2002, p.13). Com Amorim, no refrão de "Duração: currículo $\neq$ refrão $\neq$ repetição $\neq$ imaginação":

$\mathrm{Na}$ (des)ilusão da experiência, o vazio. Na (des)igualdade do encanto, as cores. No(des)ânimo da pressa, a velocidade. No (des)caso das singularidades, o corpo. No (des) amor, ex-pressão. No (des)aprender, a decepção. No (des)focar, as linhas. No (des)contar, o esquecimento. $\mathrm{Na}$ (des)pedida, o encontro. No (des)equilíbrio, a superfície. No (des)aparecimento, as diferenças. No (des)entendimento, a sensação. No (des)prender, o organismo. $\mathrm{Na}$ (des)pretensão, o pensamento. (AMORIM, 2008, p. 330)

Criação de pensamento acontecendo nos/pelos rasgos dos planos recortados no caos. Nos/pelos virtuais furos na escrita a palavra voa, mas também morre e desaparece o corpo. 


\section{revisto}

ISSN n² 2447-4266

Vol. 4, n. 1, Janeiro-Março. 2018

DOI: http://dx.doi.org/10.20873/uft.2447-4266.2018v4n1p89

\section{Desconectar o nome}

Segmentar sem silabar, apenas des-construir, desconectar o nome da coisa. Considerar a coisa em si para pensar em espaços, hiatos, dobras naquilo que nomeamos educação. Provocar o soluço da língua, exercício de gagueira na palavra Educação, abrindo brechas ao pronunciar educa-du-ca-ção; caducação... Com Deleuze, des-territorializar procedimentos, experimentar sensações invertendo os sentidos do nomeado, abrindo os poros para percepções mais integrais, de corpo inteiro.

abrir as palavras", para: "... extrair das palavras e da língua os enunciados que integram estratos e seus limiares" e "abrir as coisas", de forma a: "... extrair das coisas visibilidades como construtos próprios de um estrato, provocando a aparição do enunciado de delinqüência (ALMEIDA, 2003, p. 63).

Enunciado de delinquência que vibra nos escritos poéticos de Manoel de Barros, assim: "Sei que fazer o inconexo aclara as loucuras. Sou formado em desencontros. A sensatez me absurda. Os delírios verbais me terapeutam" (BARROS, 2006, p.49). Se, com Manoel de Barros, "para entrar em estado de árvore é preciso partir de um torpor animal de lagarto às três horas da tarde, no mês de agosto" (BARROS, 1994, $1^{\text {a }}$ parte, IX), o processo de ser uma árvore só se completa quando os galhos nascem do próprio corpo, saindo da voz. Tornarse a coisa, ser a coisa em seu estado mesmo. É o delírio da sintaxe, em que substantivos ganham qualidades inusitadas, gerando um sentido completamente novo, totalmente "desacostumado".

Ao escrever apenas o rumor das palavras, o poeta as aproxima de coisas, de objetos que podem ser quase tocados, assim: "Em dois anos a inércia e o 


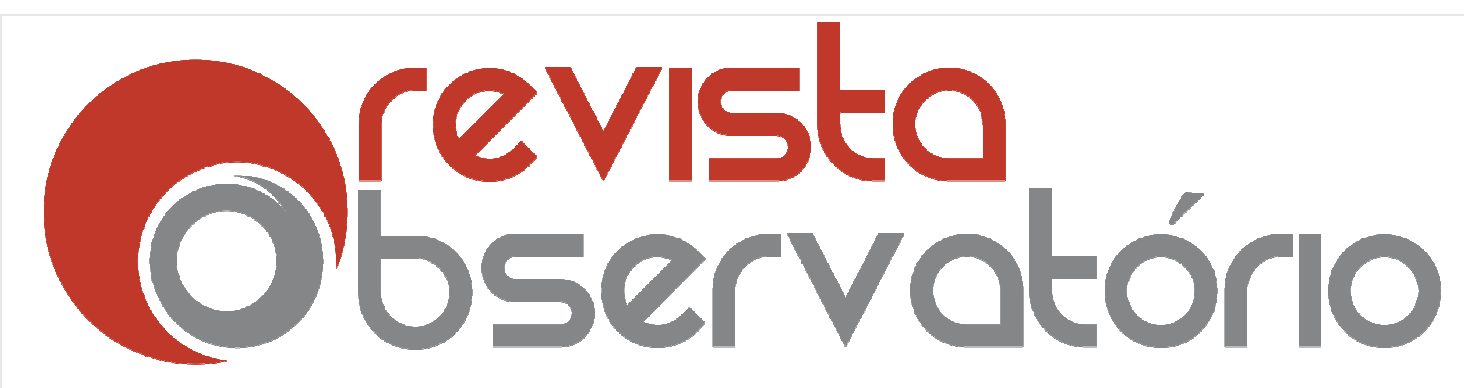

ISSN n² 2447-4266

Vol. 4, n. 1, Janeiro-Março. 2018

DOI: http://dx.doi.org/10.20873/uft.2447-4266.2018v4n1p89

mato vão crescer em nossa boca. Sofreremos alguma decomposição lírica até o mato sair na voz" (BARROS, 1994, $1^{\text {a }}$ parte, IX).

Uma escrita que não quer ocupar o espaço vazio. Uma escrita que pratica a hiatagem e se deixa escorrer, que quer cortar e esvaziar, assumindo que "Cortar não é o oposto de escorrer (barrar), mas a condição sob a qual algo escorre, em outras palavras, o fluxo não escorre senão cortado" (ZOURABICHVILI, 2004, p. 15).

\section{Não mais que uma palavra...}

Que efeitos maléficos pode ter a palavra que varia? Que efeitos maléficos pode ter uma educação que não exige a logografia da verdade? Que efeitos maléficos pode ter uma escritura que nada deseja dizer, significar? A educação percorre os campos da tradição, a linguagem gera o poder de um enunciado, a escrita se coloca no lugar da fala, mas a digressão aqui é órfã de pai e de mãe. Não pretende uma responsabilidade, ela é bastarda, morta, ausente...

O jogo da educação pode começar quando a escrita e a linguagem forem postas como possibilidades variantes. Se a educação quer legislar, codificar o corpo por todos os lados como se fosse a rainha da moral, a escrita, por outro lado, pode ser uma arma política de resistência quando coloca presente a ausência. Fissurar a educação pela escrita é saber que a mesma não compõe uma verdade.

Escapar ao escolher a conjunção $e$ para compor estranhos encontros, tensionados pelo vazio. Escapar ao criar a possibilidade de hiatar, no intransitivo verbo que substantiva a ação. Poemas se movimentam em turbilhonantes giros, girando ventos em pensamentos-educação. Ventos que se fazem poéticos, como se tempestade criadora, em Bachelard: "[...] a 


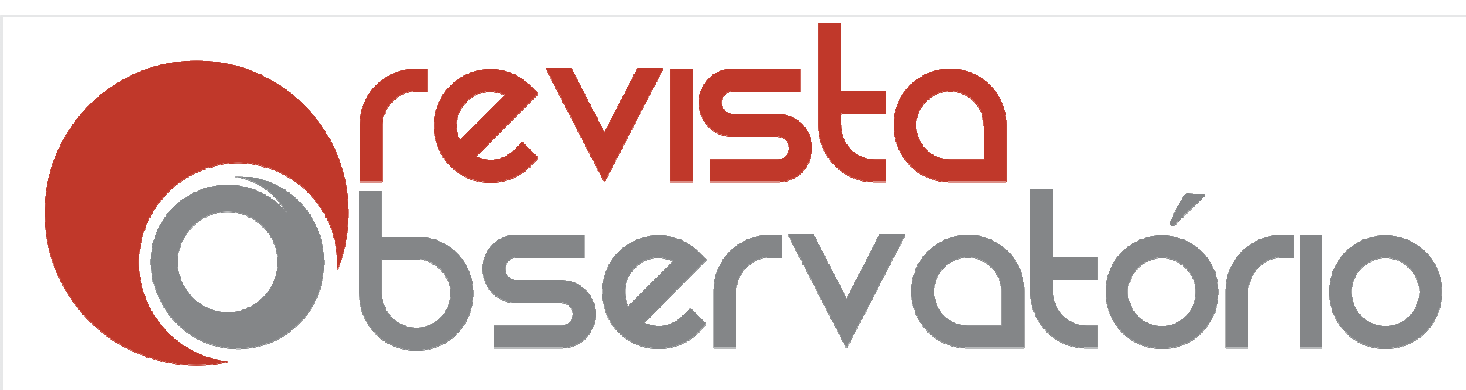

ISSN n² 2447-4266

Vol. 4, n. 1, Janeiro-Março. 2018

DOI: http://dx.doi.org/10.20873/uft.2447-4266.2018v4n1p89

tempestade criadora, o vento de cólera e de criação não são apreendidos em sua ação geométrica [...]. Nada mais pode deter o movimento turbilhonante [...]. O grito produz imagens, o grito gera a palavra vazia.

\section{Referências}

AGAMBEN, Giorgio. A comunidade que vem. trad. Antônio Guerreiro, Lisboa, Presença, (1993a).

AGAMBEN, Giorgio. Image et mémoire. Paris: Hoëbeke, 1998.

ALMEIDA, Julia. Estudos Deleuzeanos da Linguagem. Campinas: Editora da Unicamp, 2003.

AMORIM, Antonio Carlos R. de. "Duração: currículo $\neq$ refrão $\neq$ repetição \#imaginação", Educação Temática Digital (ETD), 9, 324-331, 2008.

BACHELARD, Gaston. 0 ar e os sonhos: ensaio sobre a imaginação do movimento. trad. Antonio de Pádua Danesi, São Paulo, Martins Fontes, 2001.

BARROS, Manoel de. O livro das ignorãças. Rio de Janeiro: Record, 1994.

BARROS, Manoel de. Livro sobre nada. Rio de Janeiro: Record, 2006.

BARROS, Manoel de. Memórias inventadas - A infância. São Paulo: Planeta, 2007.

DELEUZE, Gilles. A ilha deserta e outros textos. São Paulo: Iluminuras, 2004.

DELEUZE, Gilles. Conversações. São Paulo: Ed. 34, 2006.

DELEUZE, Gilles. Crítica e Clínica. São Paulo: Ed. 34, 2008.

DURAS, M. O amante. Trad. Denise Bottmann. São Paulo: Cosac Naify, 2007. 


\section{Observatónio}

ISSN n² 2447-4266

Vol. 4, n. 1, Janeiro-Março. 2018

DOI: http://dx.doi.org/10.20873/uft.2447-4266.2018v4n1p89

DELEUZE, G; PARNET, C. Diálogos. Trad. José Gabriel Cunha. Lisboa: Relógio D'àgua, 2004.

DELEUZE, Gilles. Lógica do sentido. São Paulo: Perspectiva, 2007.

DELEUZE, Gilles. Foucault, trad. Claudia Sant'Anna Martins, São Paulo, Brasiliense, 1988.

DELEUZE, Gilles. "Imanência: uma vida", In Revista Educação e Realidade 27, 2, 10-7, 2002.

DELEUZE, Gilles. \& GUATTARI, Félix. O que é a Filosofia. Trad. Bento Prado Júnior e Alberto Alonso Muñoz. São Paulo: Ed.34, 1992.

DELEUZE, Gilles. \& GUATTARI, Félix. Mil platôs: capitalismo e esquizofrenia. Volume 1, trad. Aurélio Guerra Neto e Célia Pinto Costa, São Paulo, Ed. 34, 1995.

DELEUZE, Gilles. \& GUATTARI, Félix. Mil platôs: capitalismo e esquizofrenia. Volume 3, trad. Aurélio Guerra Neto, Ana Lúcia de Oliveira, Lúcia Cláudia Leão e Suely Rolnik, São Paulo, Ed. 34, 1996.

LINS, Daniel. A Escrita Rizomática. Revista Polichinello n. 10- Por Uma Escrita Rizomática, 20 jun 2012.2 Disponível em: https://territoriosdefilosofia.wordpress.com/2014/07/18/a-escrita-rizomaticadaniel-lins/ Acessado em março de 2017.

NIETZSCHE, Friedrich. Assim falou Zaratustra. trad. Mário da Silva, Rio de Janeiro, Civilização Brasileira, 2000.

RANCIÈRE, Jacques. A partilha do sensível - estética e política. São Paulo: Ed. 34, 2012.

ROLNIK, Suely y GUATTARI, Félix. Micropolítica. Cartografias del deseo. Madrid: Traficantes de Sueños, 2006. Disponível em: http://monoskop.org/File:Guattari Felix Rolnik Suely Micropolitica Cartografias del deseo.pdf Acessado em: março de 2014.

ROMAGUERA, Alda Regina Tognini. Vida e arte e educação e(m) criações. Tese de doutorado orientada por Antonio Carlos Amorim, FE/UNICAMP, defendida em 24/11/2010. 


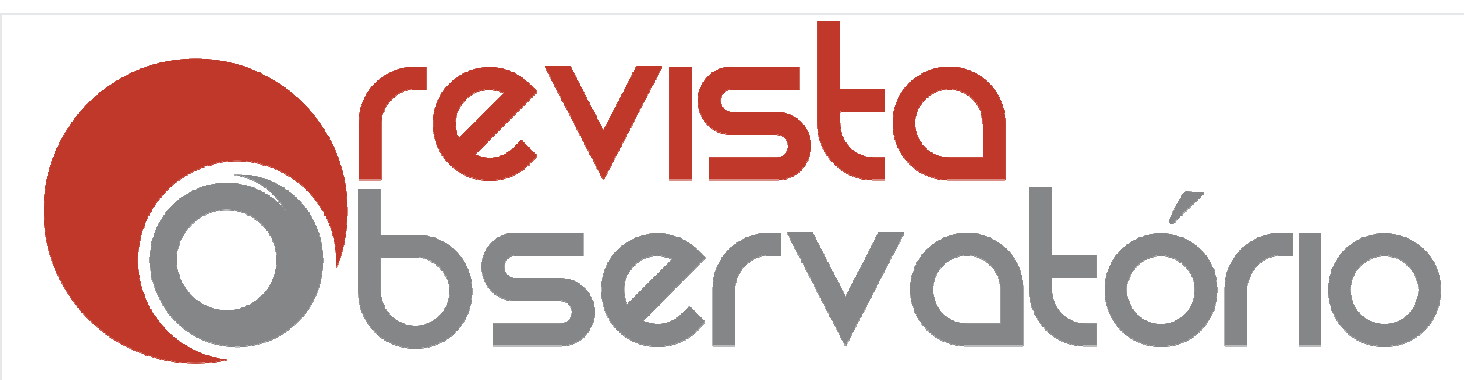

ISSN n² 2447-4266

Vol. 4, n. 1, Janeiro-Março. 2018

DOI: http://dx.doi.org/10.20873/uft.2447-4266.2018v4n1p89

SALOMÃO, Wally. Hélio Oticica: qual é o parangolé? E outros escritos. Rio de Janeiro: Rocco, 2003.

SERGUILHA, Luís. Kalahari São Paulo: Editora Ofício das Palavras, 2013.

ZOURABICHVILI, François. O vocabulário de Deleuze. Rio de Janeiro: RelumeDumará, 2004. 